DOI 10.12737/article_5b3506e7938e47.51294573

УДК 631.3

\author{
МАШИННЫЕ ТЕХНОЛОГИИ ДЛЯ ВОЗДЕЛЫВАНИЯ ХМЕЛЯ \\ Дмитриев Ю.П., Медведев В.И., Акимов А.П., Дмитриева О.Ю., Дмитриев С.Ю., \\ Максимов А.Н., Андреев В.А.
}

Реферат. В статье приведен анализ современного состояния отрасли хмелеводства в целом по России и по Чувашской Республике. Чувашия остается самым перспективным регионом для развития отрасли хмелеводства в России, где сохранено промышленное производство и уникальная коллекция сортов хмеля. Обоснована роль Чувашского НИИСХ и Чувашской ГСХА в развитии отрасли хмелеводства. Описан уровень энергообеспеченности в отечественном хмелеводстве, который намного отстает от зарубежных. Выявлено, что одной из причин низкой рентабельности отрасли хмелеводства является недостаточная механизация работ на основных технологических операциях. Используемые машины для возделывания хмеля по существующей технологии не обеспечивают на должном уровне выполнения не только современных передовых технологий, но и в полной мере существующих технологий. Рекомендованы пути подъема отрасли хмелеводства на основе внедрения в производство современных высокоэффективных малозатратных машинных технологий. Предложена усовершенствованная технология производства хмеля и машины для ее осуществления, позволяющие значительно сокращать материальные и трудовые затраты, а также способствующие повышению урожайности хмеля.

Ключевые слова: сельское хозяйство, хмелеводство, хмель, усовершенствованная интенсивная технология, комбинированная машина, вышка хмелевая, глубокорыхлитель.

Введение. Хмель - специфическая сельскохозяйственная техническая культура, шишки этого растения являются незаменимым сырьем для пивоваренной промышленности [11]. В меньшем количестве хмель используется в хлебопекарной, парфюмерной, лакокрасочной промышленности, а также при производстве отдельных видов лекарственных препаратов $[1,15]$.

В Российской Федерации годовая потребность в хмеле для производства пива составляет 8-9 тыс. тонн, и спрос на него постоянно растет. Однако отечественное сельское хозяйство может сейчас обеспечить только около $10 \%$ потребности промышленности, остальное ввозится из-за рубежа. Так, по данным Федеральной таможенной службы РФ, импорт хмеля в 2016 г. составил 5,648 тыс. тонн (на 34,748 млн. долларов), в 2017 г. - 3,723 тыс. тонн (на 37 млн. долларов) [14]. Основные поставщики хмеля на российском рынке США, Германия, Чехия, Польша [5].

В России хмель возделывается с незапамятных времен, и в недавнем прошлом его площади составляли более 4 тыс. га. Успешно хмель возделывался в 11 регионах страны. Основное производство хмеля было сосредоточено в Чувашской Республике, где ежегодно производилось до 2500-3000 тонн хмеля [12].

С 1994 года пивоваренные компании России стали переходить на закупку импортного хмеля, что привело к снижению спроса на отечественный хмель и резкому спаду производства хмеля до 300 т. Промышленное производство хмеля удалось сохранить только в Чувашской Республике.

Сегодня в Чувашии сосредоточено до 90\% всего производства хмеля в России. Небольшие объемы производства имеются в Республике Марий-Эл, Самарской области и Республике Алтай.

Хмелеводство считается самой трудоемкой отраслью сельского хозяйства. Затраты труда на возделывание хмеля на 1 га при средней урожайности 10-12 ц/га составляют 600-760 чел. дней [2].

В последние годы в Российской Федерации предпринимаются очередные шаги по возрождению отрасли хмелеводства. На правительственном уровне поставлена задача - обеспечить все пивоваренные заводы страны высококачественным отечественным продуктом. Министерством сельского хозяйства России проводится соответствующая работа: разрабатывается новая система финансовой поддержки хмелеводов, составляется подробная «дорожная карта» развития хмелеводства. В возрождение отрасли готовы вложиться и пивоваренные заводы России [4]. Решение данного вопроса потребует проведения масштабного технического перевооружения отрасли на основе внедрения современных высокотехнологических машинных технологий, модернизации имеющейся техники и разработки новых машин адаптированных к нашим погодным условиям [14].

Исходя из вышеизложенного, целью работы является усовершенствование существующей механизированной интенсивной технологии возделывания хмеля путем совмещения технологических операций за один поход машинно-тракторного агрегата, механизации навешивания поддержек стеблей хмеля, и внедрения новых агроприемов, значительно 
сокращающих материальные и трудовые затраты и повышающих урожайность хмеля.

Условия, материалы и методы исследования. Теоретической и методической основой исследования послужили труды Б.А. Доспехова, Н.А. Александрова, М.И. Крыловой, А.Р. Рупошева, А.Д. Ефимова, В.И. Юрьева, В.И. Медведева, С.А. Якимова, А.В. Короткова. В процессе работы применялся комплексный подход к изучению проблемы, использовались лабораторные и полевые методы с сочетанием агрономической оценки, отчеты по НИР Чувашского НИИСХ.

В процессе исследования применялись методы системного, структурного и сравнительного анализа, методы диалектики научной абстракции, монографического, расчетноконструктивного, других статистических приемов анализа, используемых наукой в познании социально-экономических явлений. Такой подход позволяет обеспечить обоснованность аналитических выводов и предложений.

Анализ и обсуждение результатов исследования. Чувашия остается самым перспективным регионом для развития отрасли хмелеводства. Почвенно-климатические условия Чувашии благоприятствуют возделыванию хмеля. Хмель считают растением малотребовательным к почвам. Более 95\% площади пашни в регионе относится к типам дерновоподзолистых, серых лесных и черноземных почв, что хорошо подходит для выращивания хмеля [3].

Правительством Чувашской Республики создаются организационные и финансовые условия для развития сельскохозяйственного производства [6]. Реализуется программа, рассчитанная до 2020 года, которая призвана возродить хмелеводство и предполагающая расширить территорию плантаций до 550 га [10]. Согласно этому плану, валовое производство увеличится до 500 т. Кроме того, в республике находится Федеральное государственное бюджетное учреждение «Чувашский научноисследовательский институт сельского хозяйства» (далее Чувашский НИИСХ), благодаря которому сохраняется технология и уникальная коллекция хмеля [13].

В настоящее время производством хмеля в республике занимаются 5 хозяйств (Чувашский НИИСХ - филиал ФГБНУ ФАНЦ Северо-Востока, ООО «Агрохмель», ООО
«Агроресурсы», СХПК «Выльский», Колхоз ОПХ «Ленинская искра»). Переработка чувашского хмеля осуществляется в ОАО «Чувашхмельпром» [9].

Анализ производства хмеля в 2012-2017 гг. представлен в табл. 1 .

Непременным условием эффективного развития хмелеводства в современных условиях является базирование его на научнотехнических достижениях по всем направлениям выполняемых работ - строительство модернизированных шпалерных сооружений по оптимальным для регионов системам, защиты их от вредителей и болезней на основе механизации всех трудоемких процессов.

В Чувашском НИИСХ с 1990 года ведутся работы по разработке машин для комплексной механизации технологических процессов производства хмеля.

Анализ уровня энергообеспеченности отрасли хмелеводства, проведенный в 2017 г. в целом по России и Чувашии, показывает, что существующий технический потенциал хмелеводов России не обеспечивает выполнения не только современных передовых технологий, но в полной мере существующих технологий, хмелеводы обеспечены спецтракторами менее чем на 30\%, спецтехникой - вышками, обрезчиками и другими спецмашинами - менее $10 \%$. Общий уровень износа основных производственных фондов составляет 80-90\% [7].

Восстановление хмелеводческой отрасли требует технического перевооружения сельскохозяйственного парка республики. Соблюдение целого комплекса технологических операций при производстве хмеля требует существенных затрат, в том числе и капитальных, что в последние годы не под силу многим сельхозпредприятиям.

Большинство машин, применяемых в хмелеводстве, не соответствует современным требованиям с агротехнической и энергетической точек зрения. Выпускаемые промышленностью машины узкого назначения не универсальны, имеют небольшой диапазон регулировок. Используемые машины для обработки почвы и внесения минеральных удобрений конструктивно не решены для глубокого рыхления междурядий с послойным внесением удобрений.

Существенно снизить себестоимость можно, лишь применяя комплекс взаимосвязанных

Таблица 1 - Анализ производства хмеля в Чувашкой Республике за 2012-2017 гг.

\begin{tabular}{|l|c|c|c|c|c|c|}
\hline \multirow{2}{*}{ Показатели } & \multicolumn{5}{c|}{ Годы } \\
\cline { 2 - 8 } & 2012 & 2013 & 2014 & 2015 & 2016 & 2017 \\
\hline Площадь насаждений хмеля всего, га & 349 & 308 & 271 & 245 & 173 & 177 \\
\hline Площадь насаждений хмеля в плодоносящем, га & 106 & 109 & 106 & 95 & 90,9 & 98,3 \\
\hline Валовой сбор, ц & 1863 & 1406 & 1243 & 1726 & 1386 & 1550,5 \\
\hline Урожайность, ц/га & 14 & 13 & 12 & 18 & 13,5 & 14,3 \\
\hline
\end{tabular}


механизированных приемов и организационных мероприятий, направленных на получение высокого урожая с минимальными затратами труда и средств.

Внедрение интенсивной технологии возделывания хмеля предусматривает поточное выполнение всех операций в строгой последовательности, соблюдение оптимальных сроков. При этом все виды работ должны быть выполнены при высоком уровне качества работ [16].

Интенсивная технология, несмотря на свои бесспорные преимущества перед сложившейся традиционной технологией, имеет ряд недостатков, она многозатратна за счет многократного прохода машинно-тракторного агрегата (до 20 и более раз). В результате чего, за вегетационный период зоны расположения корневой системы хмеля сильно уплотняются, доходя до 1,80 МПа. По существующей применяемой технологии за вегетационный период только междурядную обработку проводят до 6 раз.

Всесторонний анализ существующих способов и технологических операций в производстве хмеля, исследование конструкции машин для обработки почвы, внесения минеральных удобрений позволили выявить значительные резервы усовершенствования технологических операций, способных значительно улучшить качественные и энергетические показатели проводимых работ.

Достижение этих целей возможно лишь при внедрении в производство современных высокоэффективных малозатратных технологий, позволяющих увеличить производительность труда, повысить его качество, уменьшить расход топлива.

С целью усовершенствования существующей технологии необходимо совмещать технологические операции, позволяющие разработать малозатратную технологию.

Коренным отличием усовершенствованной технологии от способа возделывания хмеля по интенсивной технологии является комплексное проведение (по 4...5 операций) технологических операций за один проход машиннотракторного агрегата.

На основе теоретических и экспериментальных исследований установлено, что снижение уплотнения почвы и сокращение прямых затрат в хмелеводстве невозможны без внедрения в производство комбинированных машин, позволяющих за один проход машинно-тракторного агрегата совмещать до 4...5 операций.

С этой целью в Чувашском НИИСХ разработан и внедрен в производство уникальный роторный почвообрабатывающий агрегат РПКА-2,5 АХ [17]. Совмещение ряда техноло- гических операций за один проход машиннотракторного агрегата должно способствовать минимализации затрат и снижению уплотнения почвы.

Комбинированная машина РПКА-2,5 АХ создана на базе плуга-рыхлителя ПРВН-1,5 AX (ПРН-2,5X) и снабжена нижеследующими приспособлениями:

1. Четырьмя рыхлящими роторами для обработки рядов. Глубина обработки и ширина захвата регулируется гидравликой.

2. Туковысевающими аппаратами. Гранулированные удобрения подаются в три слоя в диапазоне 10, 20 и 30 см и 20, 30 и 40 см.

3. Насосом шестеренчатого типа НШ-5 и штангой для внесения жидких препаратов (ЖКУ, аммиачная вода) на глубину от 10 до $30 \mathrm{~cm}$.

4. Штангой для внесения гербицидов, обеспечивающей также проведение химической рамовки. Она универсальна, имеет сменные распылители, регулируется по ширине захвата.

5. Вертикальной комбинированной штангой для обработки хмельников против вредителей и болезней, обеспечивающей высоту опрыскивания до 7 метров. Дозировка расходования рабочих жидкостей при обработке хмельников и внесении гербицидов, других жидких препаратов регулируется специальной крановой системой, обеспеченной манометром и циферблатом.

6. Выравнивающим устройством для выравнивания междурядий и заделки гербицидов.

7. Обтекателями для защиты растений от повреждений.

Аналогов таких машин в хмелепроизводящих регионах мира нет.

Исследования, проведенные в Чувашском НИИСХ, показали, что усовершенствованная технология производства хмеля с применением комбинированной машины РПКА-2,5АХ, дала прибавку урожая по сравнению с контрольным вариантом (интенсивная технология) на 3,8 ц/га.

Машина предназначена для рыхления ряда и междурядья на различную глубину, локального разуглубленного внесения минеральных удобрений, обработки ядохимикатами против вредителей и болезней, внесения гербицидов, аммиачной воды, жидких комплексных удобрений (ЖКУ) с одновременной заделкой их в почву, проведения химической рамовки растений хмеля и выравнивания междурядья.

Агрегат позволяет за один проход трактора совмещать до 4-5 технологических операций. Машина проста в эксплуатации, обеспечивает работу в 2-3 вариантах, отвечает агротехническим требованиям (рисунок 1).

Практическим результатом применения 


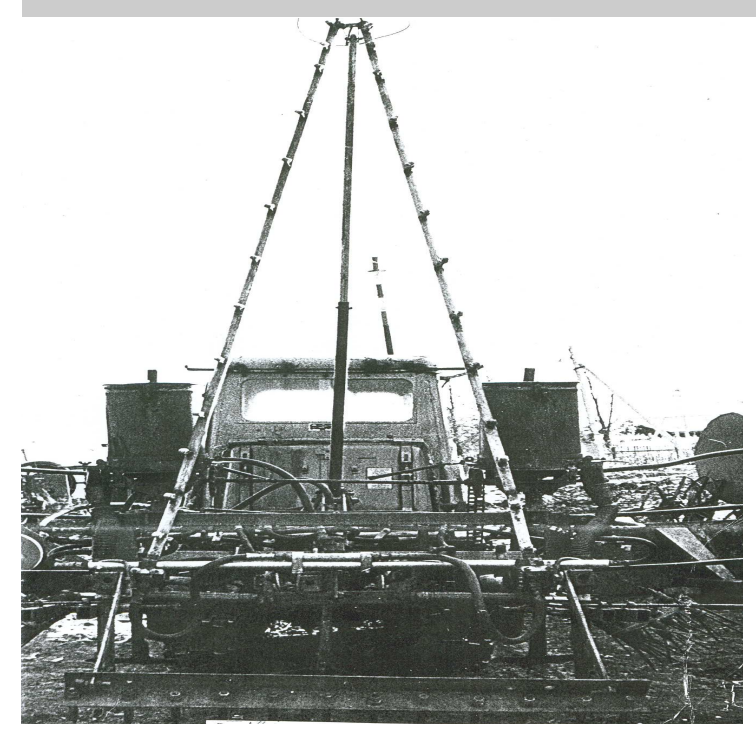

Рисунок 1 - Комбинированная машина РПКА-2,5

усовершенствованной технологии возделывания хмеля с использованием комбинированной машины РПКА-2,5 АХ является сокращение затрат труда на 1 га хмельника средней урожайности $10 . .12$ ц/га на $63,3 \%$, количество обслуживающего персонала на 64,0\%, снижение уплотненности почвы в слое 60-70 см на $62 \%$ за счет комплексной обработки хмельника совмещением операций, избавления от нерациональных рабочих проходов машиннотракторного агрегата, производительность труда увеличивается более чем в 8 раз.

Одним из самых трудоемких процессов в усовершенствованной технологии производства хмеля является навешивание поддержек стеблей растений хмеля.

Механизация навешивания поддержек стеблей хмеля является одной из важных задач в снижении трудозатрат и улучшении условий труда. Ручное навешивание весьма трудоемкое (100-130 чел.-ч/га) и выполняется, как правило, весной, при острой нехватке рабочей силы. Увеличение срока проведения весенне-полевых работ на один день по сравнению с агросроками снижает урожайность хмеля до 0,8 ц/га [16].

Для навешивания поддержек в настоящее время применяют вышку ВХ-4 (рисунок 2).

Процесс навешивания поддержек стеблей растений хмеля включает также операции: изготовление поддержек, фиксация их на шпалере и фиксация в почве.

Эта вышка предназначена не только для подвязывания поддержек стеблей хмеля на верхней продольной проволоке хмелешпалеры, а также для строительства, ремонта и обслуживания хмелевых шпалер. Тип вышки полуприцепная, производительность за смену - 2,0...3,0 га. Рабочая скорость - 1,5...1,8 км/ час.

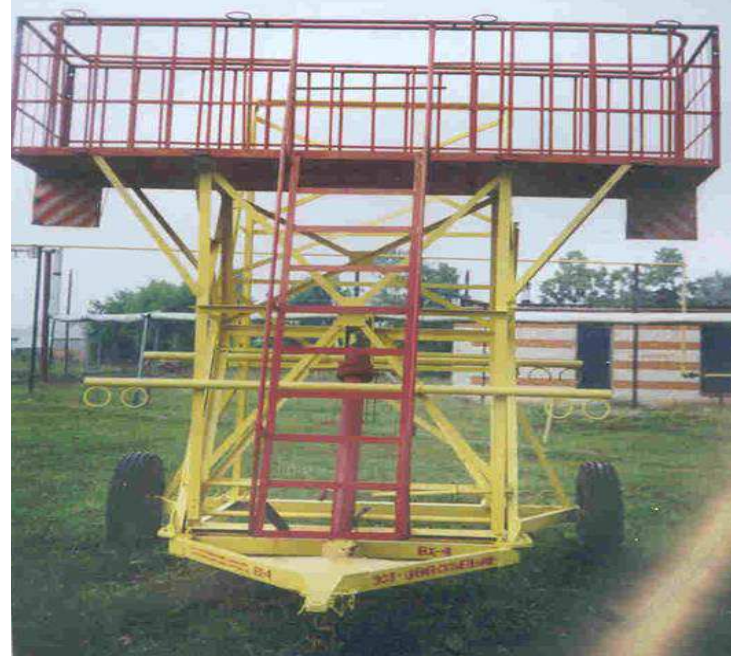

Рисунок 2 - Хмелевая вышка ВХ-4

Обслуживающий персонал - 8-9 человек, 4 рабочих на верхней площадке обеспечивают фиксацию поддержек на двух рядах за один проход трактора, 4-5 рабочих фиксируют поддержки снизу.

Механизированное навешивание исключает расходы на крючки и колышки. Производительность труда растет до 10 раз. За счет сокращения агротехнических сроков на навешивание стеблей увеличивается урожайность и качество хмеля.

Для фиксации поддержек внизу учеными Чувашского НИИСХ предложен прогрессивный способ фиксажа нижних концов поддержек. Над рядом хмеля натягивается полипропиленовый шпагат, который через каждые 3 м фиксируется к поверхности ряда «мотыльками», сделанными из 1 мм проволоки. При схеме посадки 2,5х1м для этого на один гектар требуется 6 кг полипропиленового шпагата и 4 кг проволоки.

Трудозатраты составляют 2 чел.-дня на гектар, в то же время как по традиционной технологии с использованием 5 мм металлических штыревых колышков 25 чел.-дней. Переход на новый способ является обязательным приемом для совершенствования и качественного проведения механизированной обрезки главных корневищ.

В связи со строительством в перспективе модернизированных хмельников и выращивания хмеля с переходом на большую площадь питания (3,3х1,2 м), учеными Чувашской ГСХА разработана и изготовлена новая конструкция хмелевой вышки для навешивания стеблей растений хмеля. В качестве подъемного механизма вышки использован шарнирнорычажный механизм. Производственные испытания вышки будут проводиться веснойлетом 2018 г. на участке вновь заложенного 
хмельника УНПЦ «Студенческий».

Агрономическая эффективность междурядных обработок на плантациях хмеля всегда оценивается по содержанию в почве влаги, необходимой для роста и развития растения, а также снижением уплотненности почвы в пахотном и подпахотном слоях почвы. Процесс внедрения высокоэффективной техники и перспективных технологий возделывания сельскохозяйственных культур сопровождается, как правило, интенсивным разрушением структуры и чрезмерным уплотнением почвы на большую глубину из-за частых проходов сельскохозяйственной техники и транспортных агрегатов, образованием «плужной подошвы». Это сильно проявляется при возделывании хмеля, потому что основная масса корней размещается на глубине до 50 см.

С целью улучшения водно-воздушного и микробиологической деятельности почвы, на основе проведенных исследований и производственных испытаний, предлагаем периодическое глубокое рыхление почвы в хмельниках на глубину более 0,45 м в период проведения осенних работ через каждые 3 года. Применение глубокорыхлителя с зигзагообразной стойкой для обработки почвы на глубину до 0,5 м, разработанного под руководством профессора Чувашской ГСХА В.И. Медведева, способствует уменьшению плотности, повышению водопроницаемости, аэрации, омоложению корней в активной зоне всасывания и позволяет повысить урожайность хмеля до 3 ц/га [8].

Выводы. Внедрение усовершенствованной малозатратной технологии при производстве хмеля, применение метода совмещения технологических операций с использованием комбинированной машины РПКА-2,5 АХ, навешивание поддержек с вышки, переход на новый прогрессивный метод фиксажа нижних концов поддержек в почву с использованием полипропиленового шпагата, периодическое рыхление почвы глубокорыхлителем через каждые 3 года на глубину до 50 см в период проведения осенних работ обеспечивают высокую производительность труда, способствуют уменьшению материальных затрат в 2-3 раза, проведению работ в лучшие агротехнические сроки. Возможно повышение урожайности хмеля до 3 ц/га.

Литература

1. Александров Н.А. Хмель / Н.А. Александров, М.И. Крылов, А.Р. Рупошев. - М.: Росагропромиздат, 1991. - $128 \mathrm{c}$.

2. Акимов А.П. Машины для возделывания хмеля / А.П. Акимов К.П. Майоров. - М.: Агропромиздат, 1988. - $136 \mathrm{c}$.

3. Васильев О.А. Состояние и перспективы развития современного сельскохозяйственного производства в регионе / О.А. Васильев, О.Ю. Дмитриева, В.Г. Егоров, О.А. Васильев, А.Н. Ильин // Экономика: вчера, сегодня, завтра. - 2016. - № 7. - С. 81-97.

4. Владимиров В.В. Возможности развития хмелеводства в Чувашской Республике / В.В. Владимиров, А.Е. Макушев, А.И. Захаров // Вестник Казанского ГАУ. - 2016. - №4(42). - С.15-19

5. Глобальный рынок хмеля. Рынок хмеля в России [Электронный ресурс] / Пивное дело. Международный аналитический журнал. URL.: http://www.pivnoe-delo.info/2018/02/03/rynok-xmelya/

6. Дмитриева О.Ю. Предпосылки формирования оптово-распределительного центра по сбыту картофеля и овощей в регионе // Известия Самарской государственной сельскохозяйственной академии. - 2014. - №2. C.35-39.

7. Дмитриев Ю.П. Уровень энергообеспеченности отрасли хмелеводства в регионе / Ю.П. Дмитриев, В.И. Юрьев, С.Ю. Дмитриев, Н.Н. Пушкаренко // Вестник Чувашской государственной сельскохозяйственной академии. - Чебоксары, 2017. - №3(3). - С.73-77.

8. Иванов В.М. Глубокорыхлитель с зигзагообразной стойкой для обработки почвы в междурядьях хмельника / В.М. Иванов // Механизация и электрификация сельского хозяйства. -2008. - №11. -С.16-17.

9. Медведев В.И. Современный уровень механизации возделывания хмеля в Чувашской Республике: проблемы и направления развития / В.И.Медведев, Ю.Ф. Казаков, Н.Н. Пушкаренко, П.А. Смирнов, А.О. Васильев // Известия Международной академии аграрного образования. - 2017. - №37. - С.27-31.

10. Мохнатый хмель [Электронный ресурс] / Крымская газета. URL.: https:/gazetacrimea.ru/news/mohnatii -hmel-23159.

11. Милоста Г.М. Агробиологические основы выращивания хмеля в Республике Беларусь: монография / Г.М. Милоста, В.В. Лапа. - Гродно: ГГАУ, 2010. - 286 с.

12. О развитии хмелеводства в Чувашской Республике. - Чебоксары, 2016. - 26 с.

12. Перспективная ресурсосберегающая технология производства хмеля. - М.: ФГНУ «Роинформагротех», 2008. - 52 с.

14. России не хватает собственного хмеля [Электронный ресурс] / FoodNewsWeek - продукты питания, HoReCa, общепит, АПК, сырье. URL.: http://www.foodnewsweek.ru/agro/rossii-ne-xvataet-sobstvennogoxmelya.html

15. Экономика производства хмеля [Электронный ресурс] / Economy-Ru.com. URL.:https://economyru.com

16. Юрьев В.И. Комплекс машин для возделывания хмеля в весенне-летний период / В.И. Юрьев, Ю.П. 
Дмитриев, С.Ю. Дмитриев // Сельскохозяйственные машины и технологии. - 2012. - №6. - С.45-47.

17. Юрьев В.И. Комплекс машин для возделывания хмеля в летне-осенний период / В.И. Юрьев, Ю.П. Дмитриев, С.Ю. Дмитриев // Сельскохозяйственные машины и технологии. - 2013. - №4. -С.38-41.

Сведения об авторах:

Дмитриев Юрий Петрович - кандидат технических наук, доцент, e-mail: yura.dmitriev.51@mail.ru

Медведев Владимир Иванович - доктор технических наук, професcop, e-mail: kurmyshova_olga@mail.ru,

Акимов Александр Петрович - доктор технических наук, профессор, e-mail: akimov_mechfak@mail.ru,

Дмитриева Ольга Юрьевна - кандидат экономических наук, магистрант, e-mail: 1410102010olga@mail.ru.

ФГБОУ ВО «Чувашская государственная сельскохозяйственная академия», г. Чебоксары, Россия

Дмитриев Сергей Юрьевич - кандидат технических наук, докторант, e-mail: su.dmitriev2011@yandex.ru.

ФГБНУ ФНАЦ ВИМ, г. Москва, Россия

Максимов Алексей Николаевич - кандидат физико-математических наук, доцент, e-mail: alexei.maksimow@yandex.ru

Андреев Владимир Александрович - старший преподаватель кафедры математики, физики и информационных технологий, e-mail: aiwoland7@rambler.ru

ФГБОУ ВО «Чувашская государственная сельскохозяйственная академия», г. Чебоксары, Россия

\section{MACHINERY TECHNOLOGIES FOR HOP CULTIVATION}

Dmitriev Yu.P., Medvedev VI, Akimov AP, Dmitrieva O.Yu., Dmitriev S.Yu., Maksimov A.N., Andreev V.A.

Abstract. The article gives an analysis of the current state of the hop-growing industry as a whole across Russia and the Chuvash Republic. Chuvashia remains the most promising region for the development of the hop-growing industry in Russia, where industrial production and a unique collection of hop varieties are preserved. The role of Chuvash Scientific and Research Institute of Agriculture and Chuvash State Agricultural Academy in the development of the hop-growing industry is substantiated. The level of energy supply in domestic hop-growing is described, which lags far behind the foreign ones. It was revealed that one of the reasons for the low profitability of the hop-growing industry is insufficient mechanization of work on the main technological operations. Used machines for hops cultivation using existing technology do not provide at the proper level of performance not only of modern advanced technologies, but also of fully existing technologies. Recommended ways to raise the branch of hop-growing on the basis of the introduction into production of modern highly efficient low-cost machine technologies. An improved technology for producing hops and machines for its implementation is proposed, which makes it possible to significantly reduce material and labor costs, as well as increase hop yields.

Key words: agriculture, hop-growing, hops, advanced intensive technology, combined machine, hop plant, deep loosener.

\section{References}

1. Aleksandrov N.A. Khmel. [Hop]. / N.A. Aleksandrov, M.I. Krylov, A.R. Ruposhev. - M.: Rosagropromizdat, 1991. - P. 128.

2. Akimov A.P. Mashiny dlya vozdelyvaniya khmelya. [Machines for hops cultivation]. / A.P. Akimov K.P. Mayorov. - M.: Agropromizdat, 1988. - P. 136.

3. Vasilev O.A. State and prospects of development of modern agricultural production in the region. [Sostoyanie $\mathrm{i}$ perspektivy razvitiya sovremennogo selskokhozyaystvennogo proizvodstva v regione]. / O.A. Vasilev, O.Yu. Dmitrieva, V.G. Egorov, O.A. Vasilev, A.N. Ilin // Ekonomika: vchera, segodnya, zavtra. - Economics: yesterday, today, tomorrow. 2016. - №7. - P. 81-97.

4. Vladimirov V.V. Possibilities for the development of hop growing in the Chuvash Republic. [Vozmozhnosti razvitiya khmelevodstva v Chuvashskoy Respublike]. / V.V. Vladimirov, A.E. Makushev, A.I. Zakharov // Vestnik Kazanskogo gosudarstvennogo agrarnogo universiteta. - The Herald of Kazan State Agrarian University. - 2016. - №4(42). - P. 15-19

5. Globalnyy rynok khmelya. Rynok khmelya v Rossii. / Pivnoe delo. Mezhdunarodnyy analiticheskiy zhurnal. (The global market for hops. Hops market in Russia. / Beer business. International analytical journal). Available at: http:// www.pinnoe-delo.info/2018/02/03/rynok-xmelya/

6. Dmitrieva O.Yu. Preconditions for the formation of a wholesale distribution center for the marketing of potatoes and vegetables in the region. [Predposylki formirovaniya optovo-raspredelitelnogo tsentra po sbytu kartofelya i ovoschey v regione]. // Izvestiya Samarskoy gosudarstvennoy selskokhozyaystvennoy akademii. - News of Samara State Agricultural Academy. - 2014. - №2. - P. 35-39.

7. Dmitriev Yu.P. The level of energy supply of the hop-growing industry in the region. [Uroven energoobespechennosti otrasli khmelevodstva v regione]. / Yu.P. Dmitriev, V.I. Yurev, S.Yu. Dmitriev, N.N. Pushkarenko // Vestnik Chuvashskoy gosudarstvennoy selskokhozyaystvennoy akademii. - The Herald of Chuvash State Agricultural Academy. - Cheboksary, 2017. - №3(3). - P. 73-77.

8. Ivanov V.M. Deep-cropper with a zigzag stand for cultivating the soil in the aisles between hop-crops. [Glubokorykhlitel s zigzagoobraznoy stoykoy dlya obrabotki pochvy v mezhduryadyakh khmelnika]. / V.M. Ivanov // Mekhanizatsiya i elektrifikatsiya selskogo khozyaystva. - Mechanization and electrification of agriculture - - 2008. - №11. - P. 16-17.

9. Medvedev V.I. Modern level of mechanization of hops cultivation in the Chuvash Republic: problems and directions of development. [Sovremennyy uroven mekhanizatsii vozdelyvaniya khmelya v Chuvashskoy Respublike: problemy i napravleniya razvitiya]. / V.I.Medvedev, Yu.F. Kazakov, N.N. Pushkarenko, P.A. Smirnov, A.O. Vasilev // Izvestiya Mezhdunarodnoy akademii agrarnogo obrazovaniya. - Proceedings of International Academy of Agrarian Education. 2017. - №37. - P. 27-31.

10. Mokhnatyy khmel. / Krymskaya gazeta. [Shaggy hops. / Crimean newspaper]. Available at.: https:// gazetacrimea.ru/news/mohnatii-hmel-23159. 


\section{ТЕХНИЧЕСКИЕ НАУКИ}

11. Milosta G.M. Agrobiologicheskie osnovy vyraschivaniya khmelya $v$ Respublike Belarus: monografiya. [Agrobiological bases of hops growing in the Republic of Belarus: monograph]. / G.M. Milosta, V.V. Lapa. - Grodno: GGAU, 2010. - P. 286.

12. O razvitii khmelevodstva v Chuvashskoy Respublike. [On the development of hop-growing in the Chuvash Republic]. - Cheboksary, 2016. - P. 26.

13. Perspektivnaya resursosberegayuschaya tekhnologiya proizvodstva khmelya. [Perspective resource-saving technology of hops production]. - M.: FGNU "Roinformagrotekh", 2008. - P. 52.

14. Rossii ne khvatayet sobstvennogo khmelya. / FoodNewsWeek - produkty pitaniya, HoReCa, obshchepit, APK, syre. (Russia does not have enough of its own hops. / FoodNewsWeek - food products, HoReCa, public catering, agro-industrial complex, raw materials). Available at.: http://www.foodnewsweek.ru/agro/rossii-ne-xvataet-sobstvennogo-xmelya.html

15. Ekonomika proizvodstva khmelya. / Economy-Ru.com. (Economy of hops production. / Economy-Ru.com). Available at.:https://economy-ru.com

16. Yurev V.I. A complex of machines for hops cultivation in the spring-summer period. [Kompleks mashin dlya vozdelyvaniya khmelya v vesenne-letniy period]. / V.I. Yurev, Yu.P. Dmitriev, S.Yu. Dmitriev // Selskokhozyaystvennye mashiny i tekhnologii. - Agricultural machines and technologies. - 2012. - №6. - P.45-47.

17. Yurev V.I. A complex of machines for hops cultivation in the summer-autumn period. [Kompleks mashin dlya vozdelyvaniya khmelya v letne-osenniy period]. / V.I. Yurev, Yu.P. Dmitriev, S.Yu. Dmitriev // Selskokhozyaystvennye mashiny i tekhnologii. - Agricultural machines and technologies. - 2013. - №4. - P. 38-41.

Authors:

Dmitriev Yuriy Petrovich - Ph.D. of Technical Sciences, Associate Professor, e-mail: yura.dmitriev

Medvedev Vladimir Ivanovich - Doctor of Technical Sciences, Professor, e-mail: kurmyshova_olga@mail.ru

Akimov Aleksandr Petrovich - Doctor of Technical sciences, Professor, e-mail: akimov_mechfak@mail.ru

Dmitrieva Olga Yurevna - Ph.D. of Economic Sciences, Master of Arts, e-mail: 1410102010olga@mail.ru.

Chuvash State Agricultural Academy, Cheboksary, Russia

Dmitriev Sergey Yurievich - Ph.D. of Technical sciences, doctoral student of VIM, Moscow, e-mail: su.dmitriev2011@yandex.ru.

Maksimov Aleksey Nikolaevich - Ph.D. of Physical and Mathematical Sciences, Associate Professor, e-mail: alexei.maksimow@yandex.ru

Andreev Vladimir Aleksandrovich - Senior Lecturer Mathematics, Physics and Information Technology Department, email: aiwoland7@rambler.ru

Chuvash State Agricultural Academy, Cheboksary, Russia 